\title{
Permeability testing of radiation shielding concrete manufactured at industrial scale
}

\author{
Wojciech Kubissa (D) Michał A. Glinicki - Mariusz Dąbrowski
}

Received: 15 December 2017 / Accepted: 13 June 2018/Published online: 16 June 2018

(C) The Author(s) 2018

\begin{abstract}
The effect of the composition of industrial concrete designed for radiation shielding structures on the air permeability and the diffusion of moisture was studied. The mix design for heavyweight concrete of bulk density $3168-3317 \mathrm{~kg} / \mathrm{m}^{3}$ was developed using barite and magnetite aggregate and cements blended with fly ash and blastfurnace slag. Structural elements, like columns of a height of $4 \mathrm{~m}$ and massive blocks made of mixtures with different cements were manufactured using ready mixed concrete pumped into the formwork. Core specimens were taken from the elements at different locations. The air permeability index was tested using Autoclam device. Evaluation of the quality of concrete on the basis of API results varied from "very good" to "good". The moisture distribution inside concrete specimens was equilibrated to $\mathrm{RH}=60 \pm 5 \%$. Observation of RH changes allowed to determine the moisture diffusion coefficient. Significant differences of the permeability and moisture diffusion coefficient depending on the location of the core specimens drilling and mix design of
\end{abstract}

M. A. Glinicki · M. Dąbrowski

Institute of Fundamental Technological Research, Polish Academy of Sciences, Pawińskiego 5B, 02-106 Warsaw, Poland

W. Kubissa $(\square)$

Faculty of Civil Engineering, Mechanics and

Petrochemistry, Warsaw University of Technology, 17

Łukasiewicza St., 09-400 Plock, Poland

e-mail: wojciech.kubissa@pw.edu.pl concrete were found. The $D$ coefficient provided a good reflection of the different quality of heavyweight concrete in structural elements.

Keywords Air permeability - Autoclam - Barite . Blended cement - Cracking · Heavyweight aggregate · Magnetite $\cdot$ Moisture diffusion · Radiation shielding concrete $\cdot$ Relative humidity

\section{Introduction}

The criteria for selection of ingredients and concrete mix design for radiation shielding structures include both mechanical and physical properties, the shielding against ionizing radiation, and also the impermeability to liquids and gases [1,2]. The concrete in the cover of the nuclear reactor should be impermeable to potentially radioactively contaminated air and water (due to, for example, the leakage of the reactor cooling system). A low permeability concrete can also prevent the penetration of harmful substances to the inside of the structure. This reduces the risk of corrosion of the reinforcement or the destruction of the concrete. It is important for example in the storage pools for spent fuel [3]. For the design and production of radiation shielding concrete usually the special heavy aggregates are used, such as barite, magnetite, hematite [4]. The significance of cement selection for radiation 
shielding concrete was discussed by Baran et al. [5]. Therefore there is a risk of segregation of the components of the mixture with inadequate production, transport or compaction of the mixture [6-8]. Abnormal heterogeneity of concrete can lead to local radiation surges and such cases should be effectively prevented.

The measurement of permeability of shielding concrete used in nuclear power plants is carried out by various methods. Three methods of determining the air permeability of concrete are recommended by IAEA [9], i.e. the Torrent method, the Autoclam method and the surface airflow method. The air permeability depends on the pore system but also largely on the water content in pores [10, 11]. Therefore, coefficients or correction charts are used to determine approximately the surface moisture of concrete based on the measurement of electrical resistance [12]. The relationship is difficult to establish because of the presence near-surface moisture gradients [13]. The electrical resistivity measurement is less accurate and the scatter of results is greater in comparison to the direct RH measurement. It is also highly sensitive to the cement type as a result of the variance in electrical conductivity of the pore solution, caused by the clinker phase composition, addition of supplementary cementitious materials like blastfurnace slag [14].

The air permeability determination of concrete at partial water saturation conditions corresponds to the operating conditions of radiation shielding structures. As Oxfall demonstrated [15], the representative environmental conditions are determined by the temperature of concrete from 50 to $65^{\circ} \mathrm{C}$ and the relative humidity RH from 40 to $60 \%$. The $\mathrm{RH}$ of concrete is maintained at this level even after many years of operation of nuclear reactor. An exception is the concrete layer in the immediate vicinity of the reactor. The air permeability of laboratory specimens of shielding concrete in a specific moisture state was investigated in [16]. Using the Autoclam method both significant effects of type of cement and aggregate type were demonstrated. Also the essential effects of equalization of the humidity distribution in the cross section of specimens were shown. Similar methodological observations resulted from [17], although related to the normal weight concrete. The method of preparation of $100 \mathrm{~mm}$ cylindrical specimens with uniformly distributed $\mathrm{RH}$, using the surface $\mathrm{RH}$ measurement, is also shown in [18].

In the undamaged zones of a structure the low permeability of concrete allows to prevent any significant leakage through containment building walls [19]. However, the permeability can be significantly influenced by cracks [20], therefore the effects of micro cracking on the air permeability of concrete are relevant to the integrity of containment [21]. Such effects can be experimentally studied only in the industrial scale, not on small laboratory-manufactured specimens.

The moisture movement in concrete can cause different types of volume changes. The drying shrinkage is especially important in radiation-shielding concrete because it results in tensile stresses which can cause cracking. Large cracks could reduce the performance of radiation shields [22, 23]. Excessive moisture diffusion coefficients are unfavourable, they can lead to faster drying of concrete. This may have an adverse effect on the shielding performance.

Moisture movement phenomena in cement-based porous materials are quite complex because of both physical and chemical interactions between water molecules and solid phases. The development of a holistic model of the transport phenomena is a serious challenge [24]. The transport of water is generally dominated by the molecular water diffusion. Theoretical models of moisture movement in porous media are usually based on the Fick's law [25]. New calculation models are developed for the analysis of movement of moisture in concrete [25, 26]. Magnetic resonance imaging (MRI) and other modern testing techniques allow for a better understanding of the occurring phenomena. Experimental data is used as a proof of conformity of theoretical models with the actual moisture movement in concrete [27].

The moisture diffusion coefficient in concrete is highly variable and depends on many factors. Bažant [28] draws attention to the relationship between the coefficient $D$ and the RH gradients, not specifying the resulting differences. Depending on the age of concrete the coefficient $D$ can vary by up to two orders of magnitude [29]. The influence of temperature is also very important [30]. The assumed computational model and its parameters can also cause significant differences in $D$ coefficient calculated from the same experimental data. 
The purpose of the research undertaken by the authors is to evaluate the effects of mix design of heavyweight concrete manufactured in industrial scale, intended for radiation shields, on the air permeability and the diffusion of moisture through concrete. The investigation was carried out on the specimens cut from structural elements made of concrete manufactured at a ready-mix concrete plant.

\section{Experimental}

2.1 Materials and preparation of structural elements

Concrete mixes were made in a Stetter concrete mixing plant with a filling capacity $0.75 \mathrm{~m}^{3}$. Using the truck mixer the mix was transported to the place of concreting. Concrete columns with a diameter of $400 \mathrm{~mm}$ and a height of about $4.0 \mathrm{~m}$ in the steel formwork were cast. Concrete mix was fed using a pump vehicle, the compaction was achieved using a poke vibrator. Large concrete blocks $1.0 \times 1.0 \times 0.8 \mathrm{~m}$ were cast in prepared molds with thermal insulation on the side walls and at the bottom. Concrete mixture was fed directly from the hopper of truck mixer and compacted using a poke vibrator. The composition of the concrete mixtures used for making the columns and the blocks is given in Tables 1 and 2 .
Two types of heavyweight aggregates were applied for concrete mixes: crushed magnetite (the density of $4.80 \mathrm{~kg} / \mathrm{dm}^{3}$, the content of $\mathrm{Fe}_{3} \mathrm{O}_{4}$ of about $89.7 \%$ ) supplied in two fractions $0 / 5$ and $0 / 16 \mathrm{~mm}$, and crushed barite aggregate (the density of $4.20 \mathrm{~kg} / \mathrm{dm}^{3}$, the content of $\mathrm{BaSO}_{4}$ of about $92 \%$ ) supplied as 0/16 mm fraction. Common cements, manufactured according to the European standard PN-EN 197-1, were used, both Portland cement and blended cements. The basic properties of cements are given in Table 3 .

European standard methods were used to test fresh concrete properties: the consistency, the bulk density and the temperature. Fresh mix properties are also given in Tables 1 and 2. No signs of mixture segregation were observed during mixing and fresh concrete testing. Companion standard specimens were manufactured for the compressive strength determination and for the drying shrinkage evaluation. The $150 \mathrm{~mm}$ cube specimens and prismatic $100 \times 100 \times 500 \mathrm{~mm}$ specimens were manufactured and cured following the respective procedures.

\subsection{Specimens and test methods}

Basic concrete properties were determined using European standard procedures. The compressive strength of concrete was determined on $150 \mathrm{~mm}$ cubes in accordance with PN-EN 12390-3. The specimens were stored in the high moisture temperature controlled cabinet $\left(20 \pm 2{ }^{\circ} \mathrm{C}, \mathrm{RH}>95 \%\right)$ until
Table 1 The composition $\left(\mathrm{kg} / \mathrm{m}^{3}\right)$ and properties of fresh concrete mixes used to make of the columns with a height of $4 \mathrm{~m}$

\begin{tabular}{lll}
\hline Components and properties & Mixture ID & \\
\cline { 2 - 2 } & $\mathrm{B}$ & $\mathrm{A}$ \\
\hline Cement CEM II/B-S 32.5 R & 314 & \\
Cement CEM III/A $42.5 \mathrm{~N}-\mathrm{HSR} / \mathrm{NA}$ & & 342 \\
Sand 0/2 mm & 567 & 363 \\
Crushed magnetite $0 / 5 \mathrm{~mm}$ & 786 & - \\
Crushed magnetite $0 / 16 \mathrm{~mm}$ & 1437 & - \\
Crushed barite $0 / 16 \mathrm{~mm}$ & - & 2298 \\
Water & 194 & 164 \\
Plasticizer & 2.35 & 0.61 \\
& Lubet C & Fluid optima 100 \\
Bulk density $\left(\mathrm{kg} / \mathrm{m}^{3}\right)$ & 3300 & 3168 \\
Slump $(\mathrm{cm})$ & 21.0 & 11.0 \\
Temperature $\left({ }^{\circ} \mathrm{C}\right)$ & 12 & 19 \\
$w / c$ ratio & 0.62 & 0.48 \\
\hline
\end{tabular}


Table 2 The composition $\left(\mathrm{kg} / \mathrm{m}^{3}\right)$ and properties of fresh concrete mixes T49T51 used to make massive blocks

\begin{tabular}{llll}
\hline Components and properties & \multicolumn{2}{l}{ Mixture ID } & \\
\cline { 2 - 4 } Type of cement & T49 & T50 & T51 \\
\hline Cement & CEM I 52.5 R & CEM II/B-V 32.5 R & CEM II/B-S 32.5 R \\
Water & 405 & 399 & 402 \\
Sand 0/2 mm & 201 & 198 & 199 \\
Crushed magnetite $0 / 5 \mathrm{~mm}$ & 634 & 547 & 551 \\
Crushed magnetite 0/16 mm & 1520 & 625 & 629 \\
Plasticizer $(\% \mathrm{~m} . \mathrm{c})$. & 0.5 & 1498 & 1508 \\
Bulk density $\left(\mathrm{kg} / \mathrm{m}^{3}\right)$ & 3317 & 0.5 & 0.5 \\
Slump $(\mathrm{cm})$ & 13.0 & 3269 & 3291 \\
Temperature $\left({ }^{\circ} \mathrm{C}\right)$ & 22 & 11.0 & 11.0 \\
$w / c$ ratio & 0.50 & 22 & 22 \\
\hline
\end{tabular}

Table 3 Physical properties of cements used for heavyweight concrete mixes

\begin{tabular}{|c|c|c|c|c|}
\hline Properties & CEM I 52.5R & CEM II/B-V 32.5R & CEM II/B-S 32.5R & CEM III/A $42.5 \mathrm{~N}-\mathrm{HSR} / \mathrm{NA}^{\mathrm{a}}$ \\
\hline \multicolumn{5}{|l|}{ Compressive strength (MPa) at } \\
\hline 2 days & 36.9 & 16.1 & 18.9 & 25.1 \\
\hline 28 days & 67.7 & 43.8 & 51.6 & 60.1 \\
\hline Initial setting time (min) & 164 & 325 & 224 & 212 \\
\hline Water to the standard consistency $(\%)$ & 30.0 & 27.9 & 28.4 & 28.2 \\
\hline Soundness (mm) & 0.5 & 0.7 & 0.6 & 0.4 \\
\hline Specific surface area (Blaine) $\left(\mathrm{cm}^{2} / \mathrm{g}\right)$ & 4558 & 3360 & 3751 & 3702 \\
\hline
\end{tabular}

${ }^{\mathrm{a}}$ Sulphate resistant, low alkali cement $\mathrm{Na}_{2} \mathrm{O}_{\mathrm{eq}}=0.63 \%$ according to PN-B 19707

testing. The compressive strength of concrete was determined at the age of 28 and 90 days (Table 4). Only for the series T49, T50 and T51 the compressive strength was also determined at the age of 630 days.

The shrinkage tests were performed in accordance with ISO 1920-8 modified following prEN 12390-16. Specimens were demoulded at $24 \mathrm{~h}$ after casting and placed in the drying room at the temperature of
$20 \pm 2{ }^{\circ} \mathrm{C}$ and the relative humidity of $60 \pm 5 \%$. The length change was recorded until 90 days (Table 5).

A significant strength increase was noted at the age of almost 2 years for concrete specimens manufactured with CEM II/B-V and CEM II/B-S cements and magnetite aggregate. The observed drying shrinkage results are consistent with the trends presented in [31]. A larger shrinkage was observed in concrete with

Table 4 The compressive strength of concrete (MPa) tested on $150 \mathrm{~mm}$ cube specimens (the average value and the standard deviation of 3 specimens)

\begin{tabular}{|c|c|c|c|c|c|}
\hline \multirow[t]{2}{*}{ Age (days) } & \multicolumn{2}{|c|}{ Concrete mix for column } & \multicolumn{3}{|c|}{ Concrete mix for large blocks } \\
\hline & B & A & T49 & T50 & T51 \\
\hline 28 & $35.2( \pm 1.6)$ & $45.3( \pm 2.1)$ & $54.4( \pm 1.4)$ & $49.6( \pm 1.8)$ & $48.3( \pm 1.9)$ \\
\hline 90 & $40.5( \pm 1.5)$ & $48.6( \pm 1.9)$ & $57.1( \pm 2.6)$ & $65.0( \pm 1.1)$ & $62.6( \pm 1.6)$ \\
\hline 630 & - & - & $59.2( \pm 1.7)$ & $77.2( \pm 2.4)$ & $71.5( \pm 2.2)$ \\
\hline
\end{tabular}


Table 5 Drying shrinkage of concrete $(\mathrm{mm} / \mathrm{m})$ in time (the average value and the standard deviation of 3 specimens)

\begin{tabular}{lllllllll}
\hline Concrete designation & \multicolumn{7}{l}{ Drying time (days) } \\
\cline { 2 - 9 } & 7 & 14 & 21 & 28 & 35 & 42 & 56 & 90 \\
\hline B & 0.167 & 0.27 & 0.33 & 0.389 & 0.426 & 0.434 & 0.463 & 0.513 \\
& 0.021 & 0.046 & 0.045 & 0.043 & 0.047 & 0.051 & 0.054 & 0.053 \\
A & 0.212 & 0.298 & 0.353 & 0.426 & 0.461 & 0.491 & 0.517 & 0.612 \\
& 0.062 & 0.059 & 0.053 & 0.061 & 0.063 & 0.042 & 0.049 & 0.077 \\
T49 & 0.117 & 0.211 & 0.289 & 0.342 & 0.371 & 0.388 & 0.415 & 0.471 \\
& 0.039 & 0.057 & 0.053 & 0.078 & 0.084 & 0.079 & 0.077 & 0.084 \\
T50 & 0.151 & 0.239 & 0.291 & 0.311 & 0.357 & 0.357 & 0.494 & 0.537 \\
& 0.045 & 0.049 & 0.042 & 0.048 & 0.051 & 0.040 & 0.084 & 0.092 \\
T51 & 0.200 & 0.346 & 0.383 & 0.412 & 0.422 & 0.446 & 0.461 & 0.510 \\
& 0.020 & 0.039 & 0.031 & 0.024 & 0.020 & 0.008 & 0.006 & 0.013 \\
\hline
\end{tabular}

barite aggregate as compared to shrinkage of concrete with magnetite aggregate.

Specimens for air permeability testing were taken as drilled cores from manufactured structural members made of ready mix concrete. The concrete columns were first laid down and sliced to obtain two thick disks $\phi 400$ by $170 \mathrm{~mm}$ from the top and the bottom part of a column. The location of the disks along the column height was at the distance of about $3.4 \mathrm{~m}$. The specimens A and B were drilled from these slices at the top and the bottom of manufactured columns. The companion cores drilled form these thick concrete slices were taken to make polished plane sections for aggregate grain distribution evaluation. The specimens T49, T50 and T51 were cored from three large blocks perpendicular to the top surface. The cores of $150 \mathrm{~mm}$ in diameter and about $450 \mathrm{~mm}$ in height were sectioned to obtain two cylindrical specimens of $150 \mathrm{~mm}$ high out of each core rejecting about $30 \mathrm{~mm}$ upper layer of the core All the core specimens were trimmed using water-lubricated diamond saw to obtain flat ends.

The relative humidity $(\mathrm{RH})$ in concrete was measured using Vaisala HMP44 probes with HM40 indicator. Autoclam device from Amphora Company was used to measure the Air Permeability Index (API) [32]. The modification of the API test procedure involves applying of an annular seal, between the base ring and the concrete surface, made of microgum with a thickness of $8 \mathrm{~mm}$, and also clamping a steel ring with G-clamps instead of using expansion anchors in the bored holes. The side surfaces of cylindrical core specimens were covered with a resin layer, which was impermeable to water and air. The indices API were determined at the center of each opposite, non-isolated specimen end surface. The RH and temperature probes were inserted in plastic tubes placed into drilled holes with a diameter of $16 \mathrm{~mm}$ at a certain depth from the specimen surface: 30 and $75 \mathrm{~mm}$ below the nonisolated surface of the specimens. The assumed specimen preparation procedure and the unidirectional moisture movement ensured the uniformity of specimen drying on both sides. For the analysis and calculations a symmetrical distribution of $\mathrm{RH}$ was assumed with respect to the plane passing through the center of the specimen parallel to the unprotected walls. This permitted a determination of the $\mathrm{RH}$ distribution in a specimen based on measurements at three points.

\subsection{Specimen conditioning and API, RH measurements}

In comparison to the research described in [16], a modified specimen preparation procedure was applied with a specified target $\mathrm{RH}$, uniformly distributed in specimens. The specimen conditioning and API, RH measurements were performed in several steps, including:

a. the hole drilling for placing the tubes for $\mathrm{RH}$ probe insertion,

b. the placement of moisture barrier on lateral sides of cylindrical specimens,

c. the initial measurement of API and RH of concrete before drying, 
d. the drying of specimens in the thermostatic chamber with weekly RH measurements, until the target RH achieved,

e. the placement of moisture barrier around specimens and storage of moisture-insulated specimens at controlled laboratory conditions until the moisture equilibrium achieved,

f. the measurement of API at stabilized target RH of concrete,

g. the oven drying of specimens at $105^{\circ} \mathrm{C}$ and subsequent measurements of API.

The side surface of the specimens was secured by an impermeable resin in order to provide an unidirectional transport of moisture during the drying and stabilization. The measurements of RH at the specimen surface were carried out using the device shown in Fig. 1a. The instrument consisted of a plastic plate of dimensions $100 \times 100 \times 10 \mathrm{~mm}$ and an embedded tube of $12 \mathrm{~mm}$ internal diameter for the insertion of the Vaisala probe. The plate was fixed to the surface of concrete by blu tack mass. The area of specimen surface covered with RH measurement device was approximately $80 \mathrm{~cm}^{2}$. The distance between the plate surface and the specimen surface was $3 \mathrm{~mm}$ and the volume of air in the measuring chamber was about $24 \mathrm{~cm}^{3}$. The ratio of the volume of the measuring chamber to the test area of concrete specimen is $0.30 \mathrm{~cm}$ and it is close to the ratio of $0.25 \mathrm{~cm}$ that is characteristic when using the Vaisala instrument in a hole of $16 \mathrm{~mm}$ diameter, according to the manufacturer guidelines. In comparison to the surface RH test described in [16], the increased surface of concrete specimen covered with RH measurement and the reduced volume of the measuring chamber improve the precision of concrete $\mathrm{RH}$ representation and reduce the effect of external air access during the assembly/removal of the probe.

The continuous monitoring of the surface $\mathrm{RH}$ of the specimen during the stabilization process was applied. It allows for a precise determination of time needed to reach the assumed level of $\mathrm{RH}$ alignment in the specimen volume. It has been assumed that the stabilization of RH continues until the RH difference between the surface and $30 \mathrm{~mm}$ below the surface is less than 5\%. If the stabilization time was 1.5 times longer than the drying period, the difference limit in RH was increased to $10 \%$.
Drying of concrete specimens in fixed temperature of $65{ }^{\circ} \mathrm{C}$ was conducted in a laboratory thermostatic chamber with a forced air flow. The relative humidity of air inside the thermostatic chamber was below $10 \%$. Before start of drying the RH measurements in concrete specimens at different depths were made. During the drying process $\mathrm{RH}$ was recorded in weekly intervals. Before the weekly $\mathrm{RH}$ measurements the specimens were cooled down in the laboratory for $24 \mathrm{~h}$ to the temperature of $20 \pm 2{ }^{\circ} \mathrm{C}$.

At the time of achieving the target $\mathrm{RH}$ below $65 \%$ in concrete at a depth of $30 \mathrm{~mm}$ from the surface the drying was terminated. After cooling to room temperature of $20 \pm 2{ }^{\circ} \mathrm{C}$ the specimens were tightly wrapped in three layers of aluminium foil and additional layer of stretch film. The humidity stabilization process in the specimens was carried out in a laboratory at the air temperature of $20 \pm 2{ }^{\circ} \mathrm{C}$ and $\mathrm{RH}$ $50 \pm 10 \%$. After API measurements in stabilized moisture state, the specimens were dried to a constant mass at a temperature of $105{ }^{\circ} \mathrm{C}$. Measurements of the API in heavyweight concrete were carried out in natural RH state, after RH stabilization period and after drying at $105{ }^{\circ} \mathrm{C}$.

\section{Test results}

\subsection{Results of measurement of RH distribution} in concrete

The evolution of RH distribution in the specimen B during concrete drying and $\mathrm{RH}$ stabilization period is shown in Figs. 2 and 3. The data obtained at three locations are presented assuming the symmetrical drying conditions at two ends of cylindrical specimens.

During the drying period, a rapid reduction of $\mathrm{RH}$ in the concrete surface layer by about $30 \%$ can be seen, followed by a gradual decrease of $\mathrm{RH}$ in the remaining part of the specimen. During the moisture stabilization period it can be observed that the rate of $\mathrm{RH}$ change in different specimen layers is well correlated with $\mathrm{RH}$ gradients. With larger RH differences in the initial stabilization period, the movement of moisture is much faster than in the later period when the gradients are lower.

Figure 4 shows the distribution of $\mathrm{RH}$ in specimens $\mathrm{B}$ and T49 before the drying period, just after the 

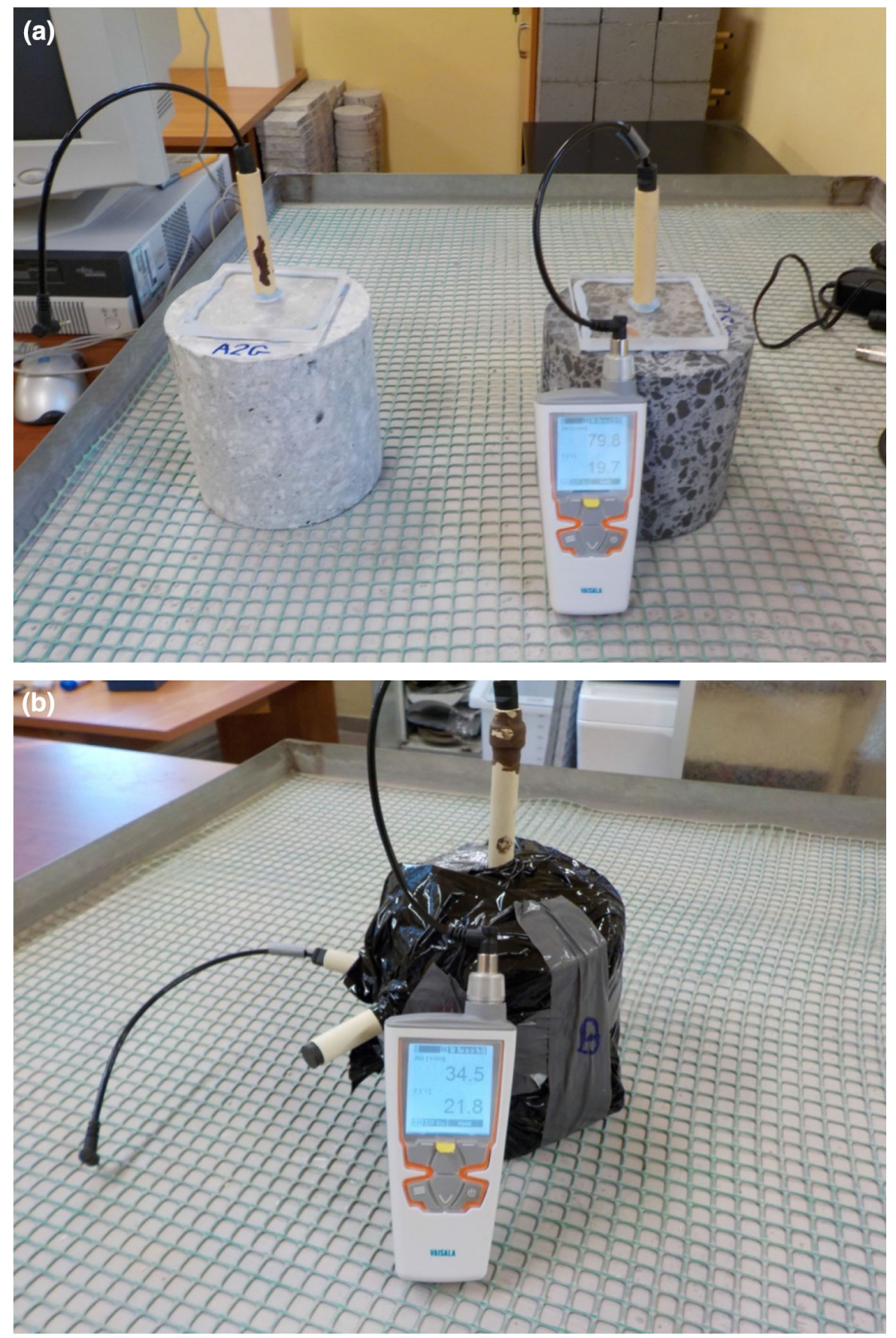

Fig. 1 The set of devices for RH measurement during concrete drying and moisture stabilization: a RH measurement at the specimen surface, $\mathbf{b}$ set of tubes at prescribed locations for insertion of Vaisala probes

drying and after the moisture stabilization period. It can be seen that after the full procedure of specimen conditioning, the RH decreased evenly by approximately $25 \%$ across the specimen.

\subsection{API measurement results}

Figure 5 shows the air permeability index of concrete specimens from the top and the bottom of columns A 


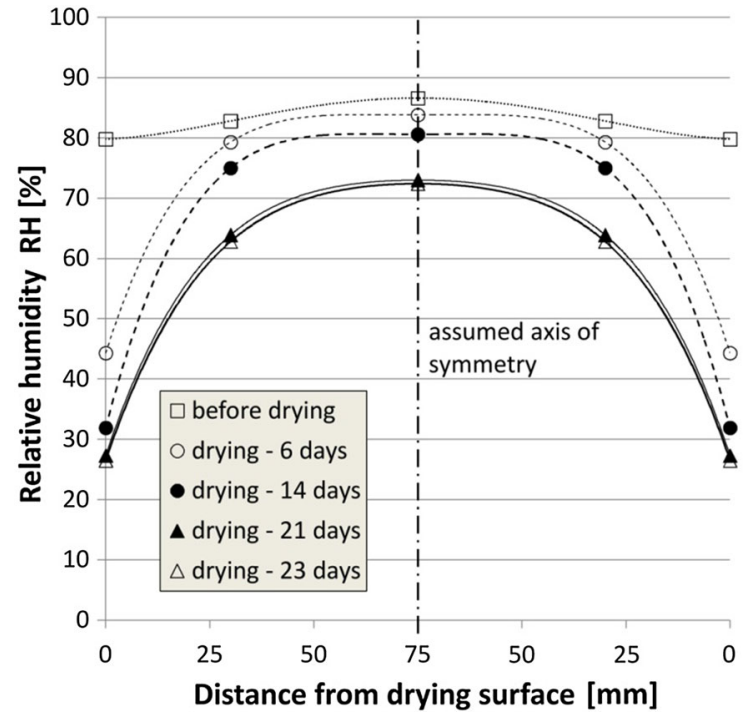

Fig. 2 Change of the RH distribution in the specimen B during the drying period at the temperature $65^{\circ} \mathrm{C}$

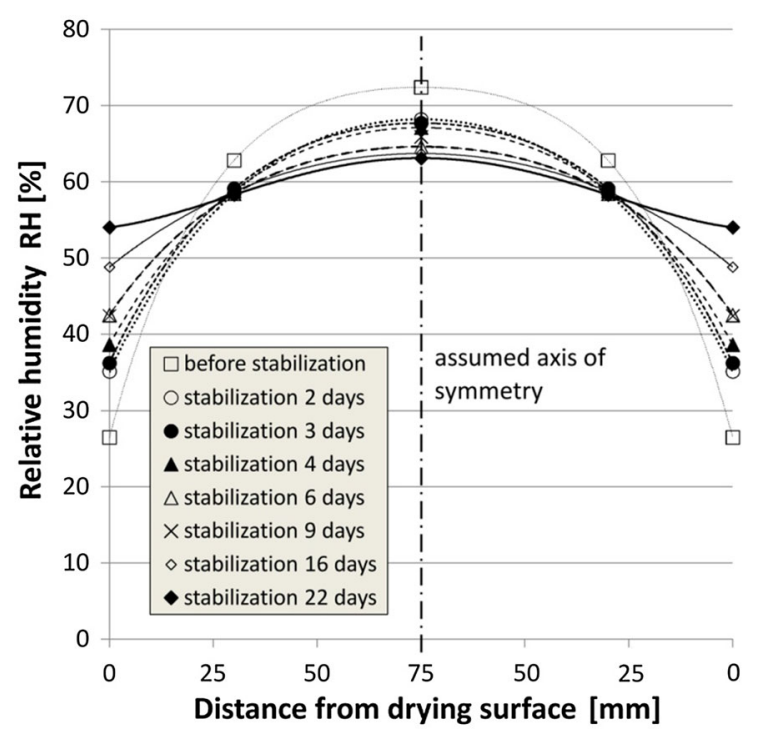

Fig. 3 Change of the RH distribution in the specimen B during the moisture stabilization period

and $\mathrm{B}$ and from the massive blocks. The average values and the standard deviation of 4 measurements are shown for each heavyweight concrete series. The data were obtained at natural RH (approx. 90\%), after the moisture stabilization at the level of RH $60 \pm 5 \%$ and after the oven drying at $105{ }^{\circ} \mathrm{C}$. For both columns a higher air permeability was observed in the upper parts than in the lower parts of the column. Such a difference at the state of stabilized RH was $31.5 \%$ for
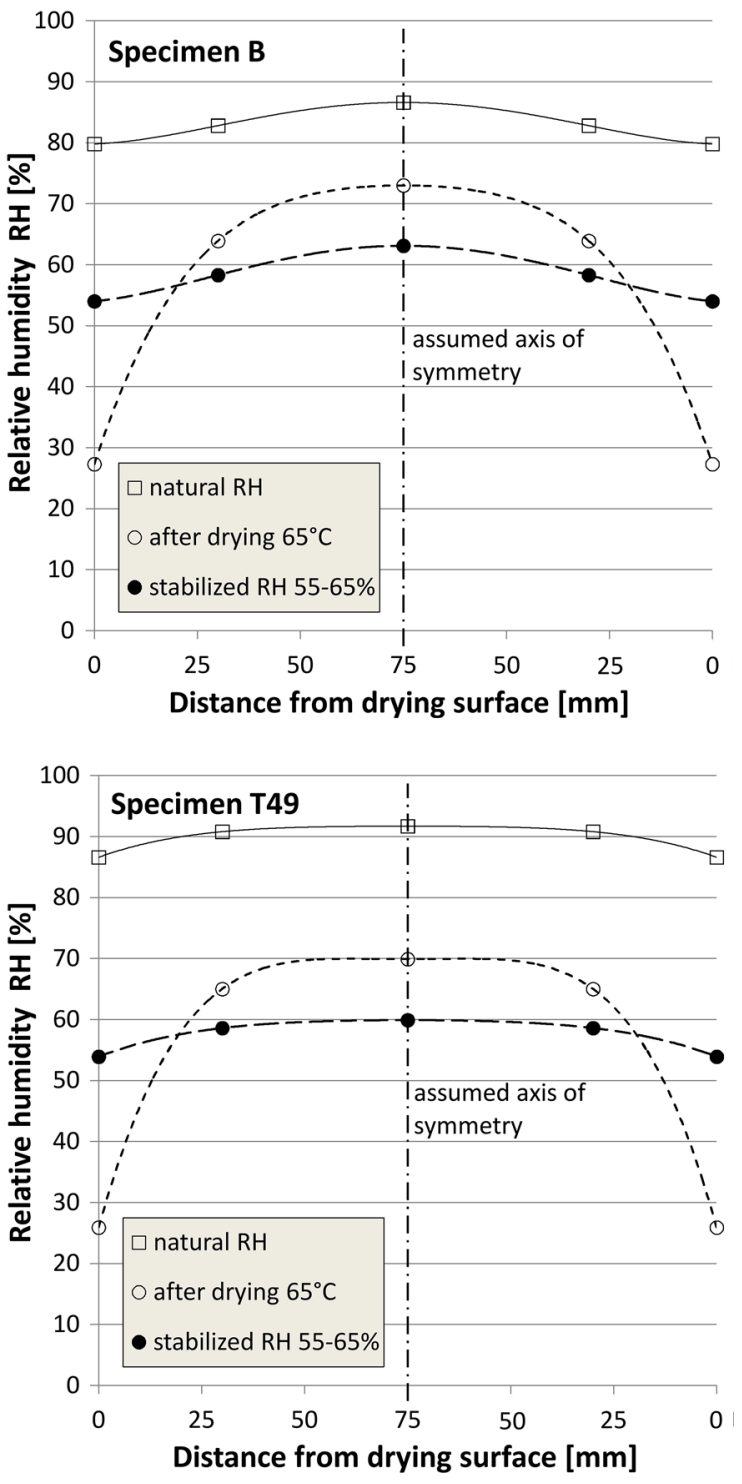

Fig. 4 RH distribution in the specimen before drying (natural state), after drying and after stabilization — the specimens B and T49

column A and $21.2 \%$ for column B. After oven drying at $105{ }^{\circ} \mathrm{C}$ such differences were 10.4 and $39.9 \%$, respectively. In the case of massive concrete blocks, similar API values were obtained in both elements with CEM II cement. The air permeability index of concrete specimens in the block manufactured using CEM I 52.5R cement was much higher. Such an increase was 136.8 and $113.2 \%$ compared to the blocks T50 and T51 at the stabilized RH. After oven drying at $105{ }^{\circ} \mathrm{C}$ the air permeability index of the 
Fig. 5 Air permeability index for concrete specimens cored from columns (a comparison of the top and bottom part of the column) and massive blocks (effects of the type of cement used)

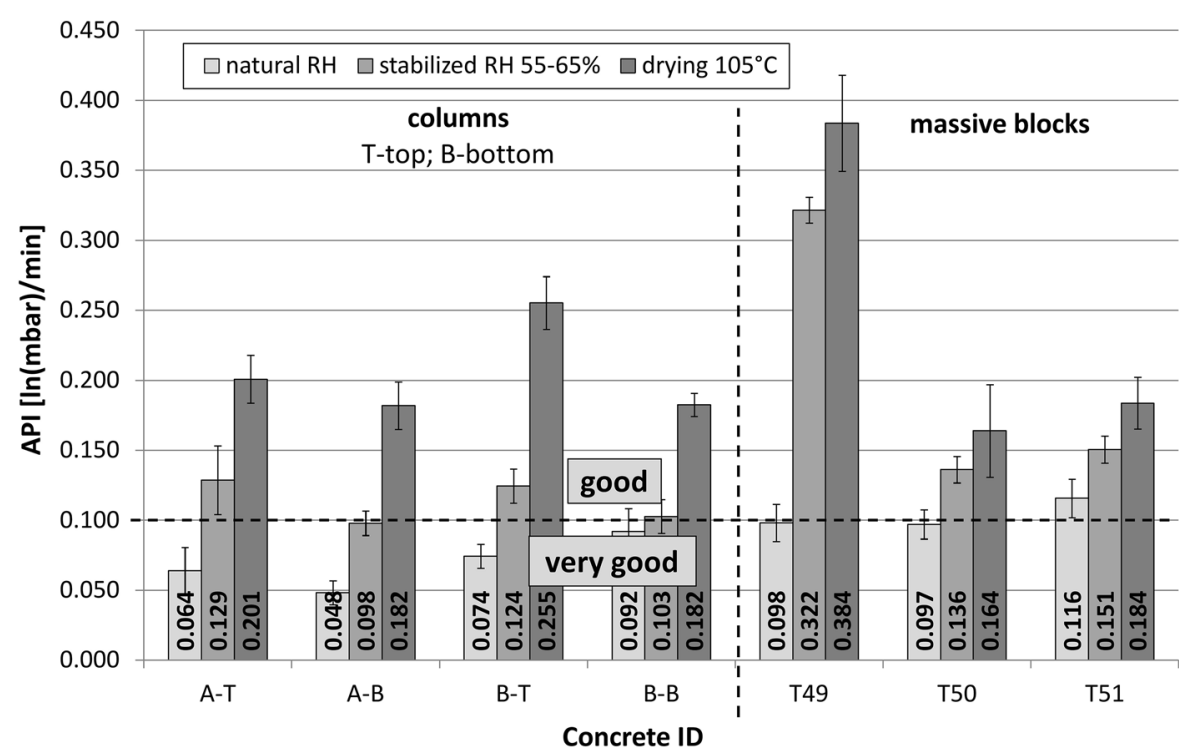

specimens increased by about $20 \%$ in respect to the RH stabilized state, i.e. from $19.3 \%$ for T49 specimens to $21.9 \%$ for T51 specimens.

Evaluation of air permeability of concrete on the basis of API was performed for the state of stabilized RH. The quality of concrete in specimens from the lower part of the column A was evaluated as "very good", and in the remaining specimens from the columns and massive blocks as "good". If such a classification was performed on the basis of API after oven drying specimens at $105^{\circ} \mathrm{C}$, the quality of concrete in all specimens would be rated "good".

\section{Analysis and discussion of results}

\subsection{Evaluation of air permeability through shielding concrete}

Basheer [32] presented the criteria of concrete classification based on API results. The criteria are established for concrete specimens dried at a temperature of $105^{\circ} \mathrm{C}$. The concrete quality evaluation on the basis of Autoclam test was presented in [33]. The API tests were performed on containment walls of a nuclear reactor. Two structures made of pre-stressed concrete were investigated. The reactor was a part of a power plant built in 1997 in southern China. The API results allowed to classify the concrete quality as good and very good. The air permeability index in one of the structures was in the range from 0.05 to $0.17 \ln (\mathrm{mbar}) /$ $\mathrm{min}$, in the other one from 0.04 to $0.15 \mathrm{ln}(\mathrm{mbar}) / \mathrm{min}$. The evaluation of the concrete quality could be seriously affected by omitting the effects of relative humidity of concrete and possible effects of carbonation.

The air permeability data obtained in the current investigation after RH stabilization were similar to results above, except T49 concrete specimens, characterized by much higher air permeability. The observed systematic difference of API between the lower and the upper part of the column (Fig. 5) can be associated with a better compaction of lower layers. The difference is more pronounced for a higher $w /$ $c$ ratio and a higher slump. Because of higher density of aggregates and higher $w / c$ ratio in the column $\mathrm{B}$, a certain degree of segregation could be possible. However no significant aggregate grain segregation was observed on the cut and polished sections of core specimens. The systematic difference of API of concrete in the massive blocks can be associated with certain degree of thermally inducted microcracking. Because of specific mould isolation the temperature field developed was favourable to enhance cracking in the case of cement of a high specific surface area and a high 2-days strength.

When comparing the air permeability test data with those obtained for the laboratory specimens made of shielding concrete with magnetite and barite [16], the following observations can be made. The API of 
concrete in the column B is significantly higher than in the lab-made concrete specimens of similar composition but $23 \%$ lower $w / c$ ratio; the difference amounted to 45.9 and $21.1 \%$ in the upper part and in the lower part of column B, respectively. The air permeability index of concrete in the upper part of column A was very similar to the API of laboratory concrete B16 [0.129 and $0.130 \ln (\mathrm{mbar}) / \mathrm{min}]$, while the API in the lower part of column A was $24.6 \%$ lower when compared to the result of laboratory concrete B16. The similar concrete mix behave as less air permeable when manufactured at an industrial scale, in particular when cast at the bottom of the column.

\subsection{Calculation of moisture diffusion coefficient}

Prediction of movement of moisture in porous media such as concrete is a complex matter, because the cementitious materials are known to have a wide range of pore sizes [34]. The pore dimensions, if assumed to be cylindrical, vary from radiuses $10^{-10} \mathrm{~m}$ (gel pores) to radiuses $10^{-2} \mathrm{~m}$ (air voids/capillary pores) [35]. The complex microstructure of pores is associated with their connectivity [36]. Depending on the pore size, the moisture movement takes place by diffusion, laminar flow and free molecular diffusion (Knudsen diffusion). In the case of greater $\mathrm{RH}$ when a part of the capillary system is filled with water there is an additional capillary transport. For the experimental determination of the moisture transport in concrete, it is usual to adopt simplified models in which one diffusion factor is used. Researchers point out that the diffusion coefficient is dependent on the $\mathrm{RH}$ of concrete [28, 37-39].

Currently, the model proposed by Bažant and Najjar [28], adopted in Model Code 2010 is in common use [40-42]. It embraces a specific model for the corresponding diffusivity coefficient $D_{h}$. The corresponding field equation is presented in Eq. 1.

$\partial h / \partial t=\operatorname{div} D_{h} \times \operatorname{grad}(\mathrm{RH})$

where $D_{h}\left(\mathrm{~cm}^{2} /\right.$ day $)$ is the diffusion coefficient (dependent on $\mathrm{RH}$ of concrete); $\mathrm{RH}$ is the relative humidity of concrete $(\%)$ (defined as the relative humidity $(\mathrm{RH})$ of the gaseous phase in equilibrium with the interstitial liquid phase in the pore network of the material [43]) and $t$ is time (days).
For the diffusion coefficient in isothermal conditions, it can be expressed as a function of the pore relative humidity $0<\mathrm{RH}<1$

$D_{h}=D_{1}\left[\alpha+\frac{1-\alpha}{1+\left[(1-\mathrm{RH}) /\left(1-\mathrm{RH}_{C}\right)\right]^{n}}\right]$

where $D_{1}\left(\mathrm{~cm}^{2} /\right.$ day $)$ is the maximum value of $D_{h}$ for $\mathrm{RH}=1 ; D_{0}\left(\mathrm{~cm}^{2} /\right.$ day $)$ is the minimum $D_{h}$ for $\mathrm{RH}=0$, $\alpha=D_{0} / D_{1}, \mathrm{RH}_{c}$ the relative pore humidity at $D_{h}$ $(\mathrm{RH})=0.5 D_{1}$ and $n$ is an exponent. Three important parameters in the formula: $\alpha(=0.05), \mathrm{RH}_{c}(=0.80)$ and $n(=15)$ are arbitrary assumed constants, given in MC2010 [44]. Assuming that in the RH range below $75 \%$ (and this is in our specimens), the relative humidity effect on the diffusivity coefficient is minimal. In our calculations we adopted the modified parameters values: $\alpha=0.10$ and $\mathrm{RH}_{c}=0.65$. Simplified calculations with a constant $D$ coefficient in the range of RH $20-75 \%$ were also performed.

$\partial h / \partial t=D \times \operatorname{grad}(\mathrm{RH})$

when calculating the $D$ coefficient, a one-directional distribution and movement of moisture and constant temperature $20{ }^{\circ} \mathrm{C}$ were assumed. It was assumed that the distribution and flow of moisture in the specimen is symmetric with respect to the plane passing through the center of the specimen, parallel to its unprotected sides. Calculations were made for the half of a specimen. The least squares method was used to determine the moisture distribution function, in the form of a polynomial of 4th degree, at the beginning and the end of the stabilization of RH (Fig. 4). An iteration number is set equal to the number of days corresponding to the moisture stabilization period in the specimen. The half of the specimen was divided into eight slices of $10 \mathrm{~mm}$ thickness. For each slice, the RH was calculated before and after stabilization. The RH gradients were calculated on each day between the individual slices $\operatorname{grad}(\mathrm{RH})_{n \text {, day }}=\mathrm{RH}_{n \text {,- }}$ day $-\mathrm{RH}_{n-1, \text { day }}(n$ from 2 to 8 ; day from 0 to the number of stabilization days- 1 , in this case day $=0.21$ ). In each iteration a further moisture distribution was calculated assuming that the moisture flowed from the element of higher RH to the neighbouring one.

$$
\begin{array}{ll}
n=1 & \mathrm{RH}_{n=1} \text {, day }+1=\mathrm{RH}_{n(=1), \text { day }} \\
& +D_{*} \operatorname{grad}(\mathrm{RH})_{n+1(=2), \text { day }} \\
n=2 \text { do } 7 & \mathrm{RH}_{n, \text { day }+1}=\mathrm{RH}_{n, \text { day }} \\
& +D_{*} \operatorname{grad}(\mathrm{RH})_{n+1, \text { day }}-D_{*} \operatorname{grad}(\mathrm{RH})_{n, \text { day }}
\end{array}
$$


$n=8$

$$
\begin{aligned}
& \mathrm{RH}_{n=8, \text { day }+1}=\mathrm{RH}_{n(=8), \text { day }} \\
& -D_{*} \operatorname{grad}(\mathrm{RH})_{n(=8), \text { day }}
\end{aligned}
$$

The $D$ coefficient was determined, minimizing the sum of the squared differences of the RH values after the stabilization determined from the matched function to the post-stabilization measurement $\left(\mathrm{RH}_{\text {stab }}\right)$ and the iteratively calculated (RH distribution day 22). Calculations were made using Microsoft Office Solver. An example of calculation of $D$ shown in Table 6.

The calculation of $D_{1}$ was carried out in the similar way, however, taking into account the effect of RH on the result, using the formulas Eqs. 1 and 2. An iteration number was equal to the number of days corresponding to the moisture stabilization period. The $D_{1}$ coefficient was determined using the $\mathrm{RH}$ values after the stabilization, determined from the matched function and the post-stabilization measurements. The sum of squared differences between the above mentioned values was minimized in an iterative procedure. Calculations were also made using Microsoft Office Solver.

\subsection{Comparison of moisture diffusion coefficients}

A large compliance was found between the moisture diffusion coefficients determined on the basis of $\mathrm{RH}$ measurements and the distribution functions obtained from the iterations. The sum of squares of the difference in experimental and calculated values was from 0.8 in series B to 43.8 in series T51. The moisture diffusion coefficients $D$ and $D_{1}$ are presented in Table 7. The maximum RH values and RH differences between the measured values in the $75 \mathrm{~mm}$ hole and the concrete surface, prior to the start of moisture stabilization in the specimens were also given. The $D_{1}$ coefficient is approximately $10 \times$ higher than $D$. In the RH range of $20-75 \%$, which occurs at the beginning of moisture stabilization, the impact of the maximum $\mathrm{RH}$ and $\mathrm{RH}$ gradient on the $D_{1} / D$ ratio is small. This ratio is largely influenced by the assumed coefficient $\alpha$. The difference in moisture diffusion coefficients of the concrete in A and B specimens was pronounced. The $D$ coefficient for concrete A $(w / c=0.48)$ was $0.094 \mathrm{~cm}^{2} /$ day. For concrete B $(w / c=0.63)$, the $D$ coefficient was $315 \%$ higher. Evaluation of concrete quality $\mathrm{A}$ and $\mathrm{B}$, based on the API and $D$, is incompatible. The API differentiation in these concretes (Fig. 5) was much lower. In the case of concrete specimens T49, T50 and T51, the API differentiation is larger (about $2 \times$ the difference between the concrete T49 with CEM I 52.5R, and T50, T51 concrete with CEM II), however, differences of $D$ coefficient are greater (more than $4 \times$ ). The lowest value of $D$ coefficient occurred in the concrete with CEM II/B-V 32.5R. For concrete with CEM II/BS 32.5R and CEM I 52.5R, the $D$ coefficients were 39 and $320 \%$ higher respectively. The $D$ coefficient better reflects the different quality of concrete resulting from a different $w / c$ ratio and probable microcracks than the API.

\section{Conclusions}

The performed investigation on radiation shielding concrete cast in structural elements resulted in the following conclusions:

The mix design for heavyweight concrete of bulk density $3168-3317 \mathrm{~kg} / \mathrm{m}^{3}$ was developed using barite and magnetite aggregate and cements blended with fly ash and blastfurnace slag. The use of CEM II/B-V and CEM II/B-S cements and $w / c$ ratio of 0.5 resulted in the concrete compressive strength of $48-50 \mathrm{MPa}$ at 28 days and its significant increase at the age of about 2 years, up to 72-77 $\mathrm{MPa}$.

An original way of measuring the RH distribution in core specimens from concrete structural elements was developed, including both measurements inside of a specimen and on its surface. The method was used to determine the RH distribution in specimens subjected to accelerated, unidirectional drying at $65^{\circ} \mathrm{C}$ and to observe changes in the $\mathrm{RH}$ distribution during storage of the specimens in sealed conditions.

The developed procedure for specimens conditioning to achieve the target RH using the surface measurement during moisture stabilization period allowed the specimen preparation time to be minimized. It was ensured by precisely determining the moment of decrease of the RH difference between the surface and the interior of the specimen to the assumed value.

The air permeability index determined on specimens with stabilized $\mathrm{RH}=60 \pm 5 \%$ showed a difference in the permeability of bottom and top part of the $4 \mathrm{~m}$ columns: the upper part of the columns 
Table 6 Method of $D$ coefficient calculation

\begin{tabular}{|c|c|c|c|c|c|c|c|c|}
\hline \multicolumn{9}{|c|}{ Solver variable cell: $D=0.39$} \\
\hline Slice number & 1 & 2 & 3 & 4 & 5 & 6 & 7 & 8 \\
\hline $\mathrm{RH}_{\text {init }}$ day 0 & 27.3 & 44.6 & 56.3 & 63.8 & 68.3 & 70.8 & 71.9 & 72.2 \\
\hline $\operatorname{grad}\left(\mathrm{RH}_{\text {init }}\right)$ day 0 & & 17.3 & 11.7 & 7.5 & 4.5 & 2.5 & 1.1 & 0.3 \\
\hline RH distribution day 1 & 34.1 & 42.4 & 54.7 & 62.7 & 67.5 & 70.3 & 71.6 & 72.1 \\
\hline $\operatorname{grad}(\mathrm{RH})$ day 1 & & 8.4 & 12.3 & 8.0 & 4.9 & 2.7 & 1.3 & 0.5 \\
\hline RH distribution day 2 & 37.3 & 44.0 & 53.0 & 61.5 & 66.7 & 69.7 & 71.3 & 71.9 \\
\hline $\operatorname{grad}(\mathrm{RH})$ day 2 & & 6.6 & 9.1 & 8.4 & 5.2 & 3.0 & 1.6 & 0.6 \\
\hline $\mathrm{RH}$ distribution day 3 & 39.9 & 44.9 & 52.8 & 60.2 & 65.8 & 69.1 & 70.9 & 71.7 \\
\hline $\operatorname{grad}(\mathrm{RH})$ day 3 & & 5.0 & 7.9 & 7.4 & 5.6 & 3.3 & 1.8 & 0.7 \\
\hline RH distribution day 4 & 41.9 & 46.0 & 52.6 & 59.5 & 64.9 & 68.5 & 70.5 & 71.4 \\
\hline $\operatorname{grad}(\mathrm{RH})$ day 4 & & 4.2 & 6.6 & 6.9 & 5.4 & 3.6 & 2.0 & 0.9 \\
\hline RH distribution day 5 & 43.5 & 47.0 & 52.7 & 58.9 & 64.2 & 67.9 & 70.1 & 71.0 \\
\hline $\operatorname{grad}(\mathrm{RH})$ day 5 & & 3.5 & 5.8 & 6.2 & 5.3 & 3.7 & 2.2 & 1.0 \\
\hline RH distribution day 6 & 44.8 & 47.9 & 52.9 & 58.6 & 63.6 & 67.3 & 69.6 & 70.7 \\
\hline $\operatorname{grad}(\mathrm{RH})$ day 6 & & 3.0 & 5.0 & 5.7 & 5.0 & 3.7 & 2.3 & 1.1 \\
\hline RH distribution day 7 & 46.0 & 48.6 & 53.1 & 58.3 & 63.1 & 66.8 & 69.1 & 70.2 \\
\hline $\operatorname{grad}(\mathrm{RH})$ day 7 & & 2.6 & 4.5 & 5.2 & 4.8 & 3.7 & 2.4 & 1.1 \\
\hline RH distribution day 8 & 47.0 & 49.4 & 53.4 & 58.2 & 62.7 & 66.2 & 68.6 & 69.8 \\
\hline $\operatorname{grad}(\mathrm{RH})$ day 8 & & 2.3 & 4.0 & 4.8 & 4.5 & 3.6 & 2.4 & 1.2 \\
\hline RH distribution day 9 & 48.0 & 50.0 & 53.7 & 58.1 & 62.3 & 65.8 & 68.2 & 69.3 \\
\hline $\operatorname{grad}(\mathrm{RH})$ day 9 & & 2.1 & 3.7 & 4.4 & 4.2 & 3.5 & 2.4 & 1.2 \\
\hline RH distribution day 10 & 48.8 & 50.6 & 54.0 & 58.0 & 62.0 & 65.4 & 67.7 & 68.9 \\
\hline $\operatorname{grad}(\mathrm{RH})$ day 10 & & 1.9 & 3.3 & 4.0 & 4.0 & 3.3 & 2.3 & 1.2 \\
\hline $\mathrm{RH}$ distribution day 11 & 49.5 & 51.2 & 54.2 & 58.0 & 61.8 & 65.0 & 67.2 & 68.4 \\
\hline $\operatorname{grad}(\mathrm{RH})$ day 11 & & 1.7 & 3.0 & 3.7 & 3.8 & 3.2 & 2.3 & 1.2 \\
\hline RH distribution day 12 & 50.2 & 51.7 & 54.5 & 58.0 & 61.5 & 64.6 & 66.8 & 68.0 \\
\hline $\operatorname{grad}(\mathrm{RH})$ day 12 & & 1.6 & 2.8 & 3.5 & 3.5 & 3.1 & 2.2 & 1.2 \\
\hline RH distribution day 13 & 50.8 & 52.2 & 54.8 & 58.0 & 61.4 & 64.3 & 66.4 & 67.5 \\
\hline $\operatorname{grad}(\mathrm{RH})$ day 13 & & 1.4 & 2.6 & 3.2 & 3.3 & 2.9 & 2.1 & 1.1 \\
\hline RH distribution day 14 & 51.3 & 52.7 & 55.0 & 58.1 & 61.2 & 64.0 & 66.0 & 67.1 \\
\hline $\operatorname{grad}(\mathrm{RH})$ day 14 & & 1.3 & 2.4 & 3.0 & 3.1 & 2.8 & 2.0 & 1.1 \\
\hline RH distribution day 15 & 51.8 & 53.1 & 55.3 & 58.1 & 61.1 & 63.7 & 65.6 & 66.7 \\
\hline $\operatorname{grad}(\mathrm{RH})$ day 15 & & 1.2 & 2.2 & 2.8 & 2.9 & 2.6 & 1.9 & 1.0 \\
\hline RH distribution day 16 & 52.3 & 53.5 & 55.5 & 58.2 & 60.9 & 63.4 & 65.3 & 66.3 \\
\hline $\operatorname{grad}(\mathrm{RH})$ day 16 & & 1.1 & 2.1 & 2.6 & 2.8 & 2.5 & 1.9 & 1.0 \\
\hline RH distribution day 17 & 52.8 & 53.8 & 55.7 & 58.2 & 60.8 & 63.2 & 64.9 & 65.9 \\
\hline $\operatorname{grad}(\mathrm{RH})$ day 17 & & 1.1 & 1.9 & 2.5 & 2.6 & 2.4 & 1.8 & 0.9 \\
\hline $\mathrm{RH}$ distribution day 18 & 53.2 & 54.2 & 56.0 & 58.3 & 60.7 & 62.9 & 64.6 & 65.5 \\
\hline $\operatorname{grad}(\mathrm{RH})$ day 18 & & 1.0 & 1.8 & 2.3 & 2.5 & 2.2 & 1.7 & 0.9 \\
\hline RH distribution day 19 & 53.6 & 54.5 & 56.2 & 58.3 & 60.6 & 62.7 & 64.3 & 65.2 \\
\hline $\operatorname{grad}(\mathrm{RH})$ day 19 & & 0.9 & 1.7 & 2.2 & 2.3 & 2.1 & 1.6 & 0.8 \\
\hline $\mathrm{RH}$ distribution day 20 & 53.9 & 54.8 & 56.3 & 58.4 & 60.5 & 62.5 & 64.0 & 64.8 \\
\hline $\operatorname{grad}(\mathrm{RH})$ day 20 & & 0.9 & 1.6 & 2.0 & 2.2 & 2.0 & 1.5 & 0.8 \\
\hline RH distribution day 21 & 54.3 & 55.1 & 56.5 & 58.4 & 60.5 & 62.3 & 63.7 & 64.5 \\
\hline
\end{tabular}


Table 6 continued

\begin{tabular}{|c|c|c|c|c|c|c|c|c|}
\hline \multicolumn{9}{|l|}{ Solver variable cell: $D=0.39$} \\
\hline Slice number & 1 & 2 & 3 & 4 & 5 & 6 & 7 & 8 \\
\hline $\operatorname{grad}(\mathrm{RH})$ day 21 & & 0.8 & 1.5 & 1.9 & 2.0 & 1.9 & 1.4 & 0.8 \\
\hline RH distribution day 22 & 54.6 & 55.3 & 56.7 & 58.5 & 60.4 & 62.2 & 63.5 & 64.2 \\
\hline $\mathrm{RH}_{\mathrm{stab}}$ & 54.0 & 55.0 & 56.6 & 58.4 & 60.2 & 61.8 & 63.1 & 63.9 \\
\hline$\left[(\mathrm{RH} \text { distribution day } 22)-\mathrm{RH}_{\mathrm{stab}}\right]^{2}$ & 0.3 & 0.1 & 0.0 & 0.0 & 0.0 & 0.1 & 0.2 & 0.1 \\
\hline \multicolumn{8}{|c|}{ Solver target cell: sum of $\left[(\mathrm{RH} \text { distribution day } 22)-\mathrm{RH}_{\mathrm{stab}}\right]^{2}$} & 0.8 \\
\hline
\end{tabular}

The example-concrete specimens from column B

Table 7 Calculated moisture diffusion coefficients $D$ and $D_{1}$

\begin{tabular}{lllrll}
\hline Concrete ID & $D\left(\mathrm{~cm}^{2} /\right.$ day $)$ & $D_{1}\left(\mathrm{~cm}^{2} /\right.$ day $)$ & $D_{1} / D$ & Max RH $(\%)$ & RH difference $(\%)$ \\
\hline A & 0.094 & 0.938 & 9.98 & 65.2 & 45.4 \\
B & 0.390 & 3.895 & 9.99 & 73.0 & 45.7 \\
T49 & 0.470 & 4.717 & 10.04 & 69.9 & 44.0 \\
T50 & 0.112 & 0.935 & 8.35 & 76.5 & 55.0 \\
T51 & 0.156 & 1.417 & 9.08 & 74.7 & 48.3 \\
\hline
\end{tabular}

exhibited a greater air permeability than the bottom part by about $20-40 \%$.

The concrete quality evaluation based on the air permeability index API, determined on specimens with uniform distribution of $\mathrm{RH}=60 \pm 5 \%$ and after drying at $105{ }^{\circ} \mathrm{C}$, was dependent on the location of the core in element and the mix design; the concrete mixes were qualified from "very good" to "good".

A moisture diffusion model in heavyweight concrete during the stage of equalization of $\mathrm{RH}$ distribution in concrete specimens, developed using Microsoft Office Solver, allowed for estimation of the moisture diffusion coefficients $D$ and $D_{1}$.

The evaluation of concrete quality, based on the API and $D$ coefficient, is found incompatible. The $D$ coefficient reflects in a better way the different quality of concrete resulting from a different $w / c$ ratio and probable microcracks.

The air permeability testing on cores from massive blocks revealed significant differences in API due to the change of cement composition: more than $100 \%$ increase was found for CEM I 52.5R in comparison with CEM II 32.5R. That could support a relationship with possible microcracking induced by high thermal gradients.

Acknowledgements The financial support from the National Center for Research and Development in Poland is gratefully acknowledged (Project PBSII/A2/15/2014 "Durability and efficiency of concrete shields against ionizing radiation in nuclear power structures").

\section{Compliance with ethical standards}

Conflict of interest The authors declare that they have no conflict of interest.

Open Access This article is distributed under the terms of the Creative Commons Attribution 4.0 International License (http:// creativecommons.org/licenses/by/4.0/), which permits unrestricted use, distribution, and reproduction in any medium, provided you give appropriate credit to the original author(s) and the source, provide a link to the Creative Commons license, and indicate if changes were made.

\section{References}

1. Bamonte P, Gambarova PG (2014) Properties of concrete required in nuclear power plants. In: Infrastructure systems for nuclear energy. Wiley, Chichester, pp 409-438

2. Kurtis KE, Xi Y, Glinicki MA et al (2017) Can we design concrete to survive nuclear environments? Concr Int 39:29-35

3. Remec I, Field KG, Naus DJ, Busby JT (2014) Concrete aging and degradation in NPPs: LWRS program R\&D progress report. Trans Am Nucl Soc 109:403-406

4. Brandt AM (2013) Application of concrete as a material for anti-radiation shielding-a review. Cem Wapno Beton 18:115-132

5. Baran T, Glinicki MA, Jóźwiak-Niedźwiedzka D (2016) The properties of special cements for shielding 
constructions in nuclear power plants. Cem Wapno Beton 21:207-215

6. ACI 221R-96 (2001) Guide for use of normal weight and heavyweight aggregates in concrete reported by ACI Committee 221. Detroit, MI

7. ACI 304.3R-96 (2004) Heavyweight concrete: measuring, mixing, transporting, and placing reported by ACI Committee 304. Detroit, MI

8. Glinicki MA (2015) Długotrwała Funkcjonalność Betonu w Konstrukcjach Osłonowych Elektrowni Jądrowych (Longterm Performance of Concrete in Shielding Structures of Nuclear Power Plants). IPPT PAN, Warszawa

9. IAEA (2016) Ageing management of concrete structures in nuclear power plants. IAEA Nucl Energy Ser NP-T3.5:1-372

10. RILEM (1999) Tests for gas permeability of concrete, TC 116-PCD: permeability of concrete as criterion of its durability. Mater Struct 32:174-179. https://doi.org/10.1007/ BF02481509

11. Liu J, Agostini F, Skoczylas F (2013) From relative gas permeability to in situ saturation measurements. Constr Build Mater. https://doi.org/10.1016/j.conbuildmat.2012. 11.092

12. Romer M (2005) Effect of moisture and concrete composition on the Torrent permeability measurement. Mater Struct 38:541-547. https://doi.org/10.1617/14321

13. Basheer P, Nolan É (2001) Near-surface moisture gradients and in situ permeation tests. Constr Build Mater 15:105-114. 0618(00)00059-3

14. Starck S, Beushausen H, Alexander M, Torrent R (2017) Complementarity of in situ and laboratory-based concrete permeability measurements. Mater Struct 50:177. https:// doi.org/10.1617/s11527-017-1037-3

15. Oxfall M, Johansson P, Hassanzadeh M (2016) Long-term hygrothermal performance of nuclear reactor concrete containments-laboratory evaluations of measurement setup, in situ sampling, and moisture flux calculations. Cem Concr Compos. https://doi.org/10.1016/j.cemconcomp. 2015.10.012

16. Kubissa W, Glinicki MA (2017) Influence of internal relative humidity and mix design of radiation shielding concrete on air permeability index. Constr Build Mater 147:352-361. https://doi.org/10.1016/j.conbuildmat.2017.04.177

17. Antón C, Climent MA, de Vera G et al (2013) An improved procedure for obtaining and maintaining well characterized partial water saturation states on concrete samples to be used for mass transport tests. Mater Struct 46:1389-1400. https://doi.org/10.1617/s11527-012-9981-4

18. Åhs M, Nilsson L, Haha M (2013) A method to determine the critical moisture level for unsaturated transport of ions. Mater Struct 48:53-65. https://doi.org/10.1617/s11527013-0167-5

19. Agostini F, Skoczylas F, Masson B (2015) Sealing of concrete confining structures of French nuclear reactors. In: International symposium in brittle matrix composites IPPT PAN, Warsaw, pp 343-352

20. Jason L, Masson B (2014) Comparison between continuous and localized methods to evaluate the flow rate through containment concrete structures. Nucl Eng Des. https://doi. org/10.1016/j.nucengdes.2014.06.010
21. Wu Z, Wong HS, Buenfeld NR (2015) Influence of dryinginduced microcracking and related size effects on mass transport properties of concrete. Cem Concr Res. https://doi. org/10.1016/j.cemconres.2014.10.018

22. Kaplan MF (1989) Concrete radiation shielding: nuclear physics, concrete properties, design and construction. Longman Scientific \& Technical, New York

23. Gencel O, Brostow W, Ozel C, Filiz M (2010) Concretes containing hematite for use as shielding barriers. Mater Sci 16:249-256

24. Gustavsson C, Piculell L (2016) Isotherms and kinetics of water vapor sorption/desorption for surface films of polyion-surfactant ion complex salts. J Phys Chem B 120:6778-6790. https://doi.org/10.1021/acs.jpcb.6b02983

25. Zeng Q, Xu S (2017) A two-parameter stretched exponential function for dynamic water vapor sorption of cement-based porous materials. Mater Struct Constr 50:1-13. https://doi. org/10.1617/s11527-017-0997-7

26. Dong H, Gao P, Ye G (2017) Characterization and comparison of capillary pore structures of digital cement pastes. Mater Struct 50:154. https://doi.org/10.1617/s11527-0171023-9

27. Enjilela R, Cano-Barrita PFJ, Komar A et al (2017) Monitoring steady state moisture distribution during wick action in mortar by magnetic resonance imaging (MRI). Mater Struct. https://doi.org/10.1617/s11527-017-1017-7

28. Bažant ZP, Najjar LJ (1972) Nonlinear water diffusion in nonsaturated concrete. Cem Concr Res 5:3-20. https://doi. org/10.1007/BF02479073

29. Zhang J, Hou D, Gao Y, Wei S (2011) Determination of moisture diffusion coefficient of concrete at early age from interior humidity measurements. Dry Technol 29:689-696. https://doi.org/10.1080/07373937.2010.528106

30. Kang ST, Kim JS, Lee Y et al (2012) Moisture diffusivity of early age concrete considering temperature and porosity. KSCE J Civ Eng 16:179-188. https://doi.org/10.1007/ s12205-012-1445-4

31. Bažant ZP, Donmez A (2016) Extrapolation of short-time drying shrinkage tests based on measured diffusion size effect: concept and reality. Mater Struct 49:411-420. https://doi.org/10.1617/s11527-014-0507-0

32. Basheer PAM (2001) Permeation analysis. Handb Anal Tech Concr Sci Technol Princ Tech Appl. https://doi.org/ 10.1016/B978-081551437-4.50019-9

33. Zheng Y, Li H (2011) Evaluation of protective quality of prestressed concrete containment buildings of nuclear power plants. J Cent South Univ Technol 18:238-243. https://doi.org/10.1007/s11771

34. Oliveira M, Azenha M, Lourenço PB (2016) Numerical simulation of humidity fields in concrete. In: International RILEM conference on materials, systems and structures in civil engineering. Conference segment on moisture in materials and structures, Lyngby, Denmark, pp 213-222

35. Jennings HM, Bullard JW, Thomas JJ et al (2008) Characterization and Modeling of pores and surfaces in cement paste: correlations to processing and properties. J Adv Concr Technol 6:5-29

36. Zhang Z (2014) Modelling of sorption hysteresis and its effect on moisture transport within cementitious materials. École Doctorale Sciences, Ingénierie et Environnement, Paris Est, Paris 
37. Pihlajavaara SE (1968) Studies of the effect of gravitation on drying with special reference to concrete. J Eng Phys Thermophys 14:208-217

38. Hedenblad G (1997) Use of mercury intrusion porosimetry or helium porosity to predict the moisture transport properties of hardened cement paste. Adv Cem Based Mater 6:123-129. https://doi.org/10.1016/S1065-7355(97) 81595-7

39. Huisman JA, Sperl C, Bouten W, Verstraten JM (2001) Soil water content measurements at different scales: accuracy of time domain reflectometry and ground-penetrating radar. J Hydrol 245:48-58

40. Holmes N, West RP (2013) Enhanced accelerated drying of concrete floor slabs. Mag Concr Res 65:1187-1198. https:// doi.org/10.1680/macr.13.00142
41. Vinkler M, Vítek JL (2014) Drying concrete: experimental and numerical modeling. J Mater Civ Eng 28:1-8. https:// doi.org/10.1061/(ASCE)MT.1943-5533.0001577

42. Zhang X, Zhao H (2015) Characterization of moisture diffusion in cured concrete slabs at early ages. Adv Mater Sci Eng 2015:1-10. https://doi.org/10.1155/2015/154394

43. Baroghel-Bouny V, Mainguy M, Lassabatere T, Coussy O (1999) Characterization and identification of equilibrium and transfer moisture properties for ordinary and high-performance cementitious materials. Cem Concr Res 29:1225-1238. https://doi.org/10.1016/S0008-8846(99) 00102-7

44. Fib (2013) Fib model code for concrete structures 2010. https://doi.org/10.1002/9783433604090 